\title{
Peculiarities of soft biological tissue perforation induced by near infrared laser radiation with optic fiber delivery
}

\author{
Alexandr K. Dmitriev, Alexey N. Konovalov*, Vladimir N. Kortunov, and Valerii A. Ulyanov \\ Institute of Photonic Technologies, Federal Scientific Research Centre 'Crystallography and Photonics' of the Russian \\ Academy of Sciences, 2 Pionerskaya Str., Moscow, Troitsk 108840, Russia \\ * e-mail: ank27.ift@mail.ru
}

\begin{abstract}
The authors studied the process of perforation of soft biological tissue by continuous near infrared lasers $(0.98 \mu \mathrm{m}, 1.56 \mu \mathrm{m}$ and $1.94 \mu \mathrm{m})$ with optic fiber delivery. Fiber drag force (FDF) during perforation of soft biological tissue was studied. Specific characteristics of laser radiation heat impact on the tissues surrounding the laser channel were examined. Three perforation modes were observed: mechanical perforation mode, intense evaporation and tissue destruction mode, "free" perforation mode. In the first mode, FDF is almost identical to FDF in the absence of radiation. In the second mode, FDF is significantly lower than FDF during laser radiation power of $\mathrm{P}=0$. In the third perforation mode, the formed channel becomes wider than the fiber diameter due to intense tissue evaporation and burning, and FDF is close to or below the sensitivity limit of the force sensor. The effect of burnt tissue deposit at the fiber tip on the laser perforation process was studied. (C) 2018 Journal of Biomedical Photonics \& Engineering.
\end{abstract}

Keywords: fiber laser; laser perforation; biological tissue; regeneration.

Paper \#3297 received 2 Aug 2018; revised manuscript received 25 Aug 2018; accepted for publication 25 Aug 2018; published online 12 Sep 2018. doi: 10.18287/JBPE18.04.030301.

\section{References}

1. I. I. Berishvili, Transmyocardial Laser Revascularisation, GEOS, Moscow, Russia (2016) [in Russian]. ISBN 978-5-89118-703-0.

2. D. I. Alyokhin, A. A. Fokin, "Prospects of using high-intensity laser radiation for the treatment of chronical ischemia of extremities," Patologiya krovoobrashcheniya i kardiokhirurgiya 2, 88-92 (2005) [in Russian].

3. S. V. Kapralov, I. A. Melnikova, U. G. Shapkin, and V. V. Alipov, "Experimental modeling of laser fenestration of the liver," Bjulleten' meditsinskih Internet-konferentsij 11(2), (2011) [in Russian].

4. I. A. Shved, T. E. Vladimirskaya, A. V. Vorobey, O. P. Shorez, S. V. Alexandrov, and A. C. Shuleiko, "Liver tissue regeneration after laser coagulation," Zdravookhraneniye (Belarus) 3, 4-8 (2014) [in Russian].

5. L. V. Astahova, E. N. Ignat'eva, E. S. Golovneva, R. U. Giniatullin, and T. G. Kravchenko, "Morphofunctional changes in the foci of laser destruction of the liver, kidney, spleen (experimental study)," Laser medicine 20(1), 50-54 (2016) [in Russian].

6. V. Tuchin, Tissue optics. Light scattering methods and instruments for medical diagnosis, SPIE press, Belingham, Washington, USA (2012).

7. L. Kou, D. Labrie, and P. Chylek, "Refractive indices of water and ice in the $0.65-2.5 \mu \mathrm{m}$ spectral range," Applied Optics 32(19), 3531-3540 (1993).

8. B. I. Sandler, L. N. Suljandziga, V. M. Chudnovskij, V. I. Jusupov, O. V. Kosareva, and V. S. Timoshenko, Perspectives of treatment of discogenic compression forms of lumbosacral radiculitis with the help of puncture non-endoscopic laser operations, Dal'nauka, Vladivostok, Russia (2004) [in Russian]. ISBN: 5-8044-0443-1.

9. V. I. Yusupov, V. M. Chudnovskii, and V. N. Bagratashvili, "Laser-induced hydrodynamics in water-saturated biotissues: 2. Effect on delivery fiber," Laser Physics 21(7), 1230-1234 (2011). 
10. V. V. Elagin, M. A. Shahova, M. M. Karabut, D. S. Kuznetsova, V. I. Bredihin, N. N. Prodanets, L. B. Snopova, O. S. Baskina, A. V. Shahov, and V. A. Kamenskij, "Evaluation of the cutting properties of a laser scalpel equipped with a highly absorbing coating of an optical fiber," Sovremennye tehnologii v meditsine 7(3), 56-60 (2015) [in Russian].

11. H.-P. Berlien, G. J. Müller (eds.), Applied Laser Medicine, Springer-Verlag, Berlin (2003).

12. J. T. Walsh, T. F. Deutsch, "Pulsed $\mathrm{CO}_{2}$ laser ablation of tissue: effect of mechanical properties," IEEE Transactions on Biomedical Engineering 36(12), 1195-1200 (1989).

13. V. A. Berezovskii, N. N. Kolotilov (eds.), Biophysical Characteristics of Human Tissues, Naukova dumka, Kiev, USSR (1990) [in Russian].

14. V. L. Utkin, Biomechanics of physical exercises, Prosveschenie, Moscow (1989) [in Russian].

\section{Introduction}

Use of high intensity laser radiation for stimulation of tissue regeneration in vital human organs through creation of deep laser channels in biological tissues is one of the promising medical trends. In particular, this approach to coronary heart disease treatment allowed to develop an efficient method for laser myocardium revascularisation, ensuring its stimulation and long-term angiogenesis [1]. Laser perforation is also becoming a popular method of stimulating regeneration processes in other soft biological tissues. In particular, positive effect of ischemic lower limb laser revascularization with 0.98 and $1.06 \mu \mathrm{m}$ radiation delivered by optic fiber is now known. The positive effect lasts for up to 6 months with further deterioration of the patients' clinical status [2]. Laser regeneration of cirrhotic rat liver has been performed with semiconductor laser radiation (wavelength $1.06 \mu \mathrm{m}$ ): it resulted in liver regeneration with formation of microcapillaries and bile ducts in the area of laser perforation with optic fiber [3]. Active work is underway to find optimal conditions for laser regeneration of this vital organ in humans $[4,5]$.

Two methods have become popular for laser formation of deep channels: 1) focused radiation in single pulse mode; 2) use of optic fiber, where perforation is carried out by moving the optic fiber with set speed into the depth of biological tissue. Obviously, these are two different approaches resulting in different physical effects in the area of perforation, and therefore different tissue and body responses to such impacts are to be expected.

If tissue is perforated by focused radiation, the channel is formed through tissue evaporation, while optic fiber perforation may include a combination of actions: mechanical impact of the optic fiber upon the tissue and its evaporation by laser radiation. Near infrared laser radiation sources with wavelength of $0.9 \mu \mathrm{m}$ to $2 \mu \mathrm{m}$ are most often used for optic fiber perforation of biological tissues. In this spectral range, the absorption coefficient of soft water-containing tissues (water content $70 \%$ and more) can vary considerably [6], since water in this range has absorption bands. For example, for the widely used wavelengths of laser sources, the absorption coefficient of water differs by orders of magnitude: it is $0.5 \mathrm{~cm}^{-1}$ for $0.98 \mu \mathrm{m}, 10 \mathrm{~cm}^{-1}$ for $1.56 \mu \mathrm{m}$ and $135 \mathrm{~cm}^{-1}$ for $1.94 \mu \mathrm{m}$ [7]. Consequentially, the process of biological tissue perforation may go differently within this wave range, both in conditions of spatial and subsurface absorption of laser radiation power by the biological tissue. Another specific characteristic of contact perforation of biological tissue with optic fiber is the changing conditions of radiation heat impact, both due to the effect of burnt tissue deposit at the fiber tip, naturally occurring directly in the process of biological tissue perforation, and as a result of special absorbing coating created at the fiber tip or fiber tip blackening $[8,9,10]$.

Thus, laser perforation of biological tissue performed through optic fiber may result in different physical phenomena, depending on the impact conditions. However, physical aspects and specific characteristics of deep channel formation in biological tissues induced by optic fiber have not been sufficiently described in scientific literature.

The purpose of this research is the comparative study of biological tissue perforation by near infrared laser radiation with optic fiber delivery in various impact modes.

\section{Materials and methods}

CW-pumped lasers were used as sources of laser radiation: 1 - semiconductor laser with power up to $10 \mathrm{~W}$ and $0.98 \mu \mathrm{m}$ wavelength (Ltd Company "RIK"); 2 - fiber optic multimode laser with $1.56 \mu \mathrm{m}$ wavelength and power up to $10 \mathrm{~W}$ (NPO "IRE-Polus"); 3 - fiber optic multimode laser with $1.94 \mu \mathrm{m}$ wavelength and power up to 15 W (NPO "IRE-Polus").

Multimode fiber with diameter of $600 \pm 30 \mu \mathrm{m}$ was used for radiation delivery. Output power applied to the biological tissue was measured by FieldMaster (Coherent) power meter. A655sc (FLIR) thermal camera was used to measure the temperature of the fiber tip; it was equipped with an extra lens to amplify and obtain an image with resolution of $50 \mu \mathrm{m}$ per pixel.

A mechanic sensor system (MSS) (Fig. 1) was created in order to study the process of biological tissue perforation by near infrared laser radiation with optic fiber delivery, which registered biological tissue drag force during its perforation with optic fiber.

This system included mechanic sensor unit 4 to convert fiber drag force to voltage using a force sensor and analog-to-digital converter 6 to record and analyze 
the signal on a PC 8 . The sensitivity of this system was $(69 \pm 1) \mathrm{mV} / \mathrm{N}$.

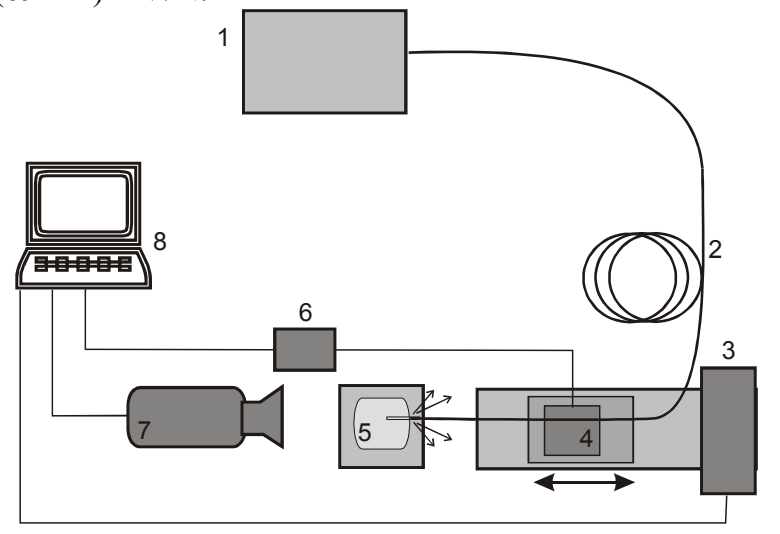

Fig. 1 Schematic diagram of the experimental setup. 1 - fiber laser; 2 - multimode fiber; 3 - motorized linear translator; 4 - mechanic sensor system; 5 - biotissue; 6 - analog-to-digital converter; 7 - thermal camera; 8 - PC.

$15 \times 10 \times 5 \mathrm{~mm}$ samples of fresh pig muscle tissue in vitro were used as the target. The tissue was obtained and used within $48 \mathrm{~h}$ post mortem. The samples were stored at $0-4{ }^{\circ} \mathrm{C}$ and at controlled humidity. The samples were placed on a stationary platform. The samples were perforated by moving the fiber into the depth of the tissue by a motorized linear translator 3 (Fig. 1) with set speed. The biological tissue samples were pierced. After perforation the samples were frozen in order to fix the form of the laser channel. After this, longitudinal and cross sections were made in the channel area, and the channel diameter and the size of the thermal damage area (TDA) in the tissue surrounding the channel were measured. Tissue TDA included two zones: carbonization zone and tissue coagulation zone. These zones were determined on change of tissue color after perforation. Carbonization zone adjacent to laser channel wall have black-and-brown color. Coagulation zone have whitish color. Such tissue color changes at temperatures above $60{ }^{\circ} \mathrm{C}$ - this is caused by protein denaturation [10]. TDA size was determined as the distance from the laser channel wall to the border of the whitish tissue. Channel geometry and the size of the thermal damage area (TDA) of the biological tissue were determined using an MBS-10 stereoscopic microscope with 100x magnification.

\section{Results and Discussion}

Fig. 2 shows typical time sweeps of the MSS signal during muscle tissue perforation. The data are given for a laser with $0.98 \mu \mathrm{m}$ wavelength and $0.5 \mathrm{~mm} / \mathrm{s}$ fiber movement speed. Three patterns may be distinguished on the tissue fiber drag force (FDF) time curve during perforation: 1) continuous increase of the drag force; 2) signal fluctuation in reference to the average level; 3) rapid decrease of the signal.

This FDF behavior may be explained as follows. The registered drag force of the tissue during its perforation by the fiber is made up of two components: drag force at the fiber tip and friction at the fiber's lateral surface during its movement inside the channel in the tissue. During the initial period, after the fiber touches the tissue surface, the signal starts to gradually increase due to tissue contraction. The signal continues to increase until FDF remains insufficient to make a hole in the tissue. In the extreme case, when laser radiation power is zero, the signal continues to increase until the force exceeds tensile strength of biotissue. The second pattern in the MSS signal is due to the fact that the pressure force at the fiber tip is sufficient to tear the tissue and start forming a hole. There are significant FDF fluctuations in this pattern. This is explained by intermittent tissue contraction, followed by a power drop during the next local tissue tear at the fiber tip. The fluctuations may also be caused by the non-steady process of tissue evaporation near the fiber tip. Herewith, intensive ejection of tissue destruction products from the entrance hole was occasionally observed in the form of smoke and vapor (due to tissue water evaporation).

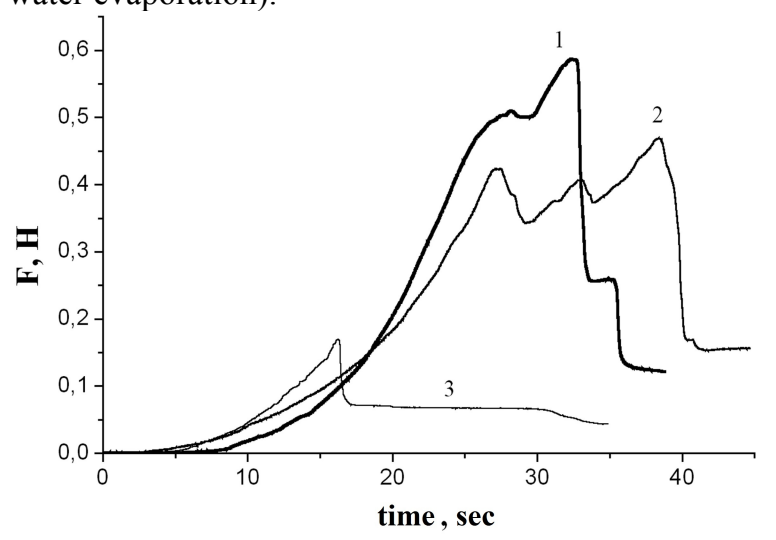

Fig. 2 FDF as a function of time in the perforation of muscle tissue by laser fiber at different radiation powers $(1-1.7 \mathrm{~W} ; 2-2.3 \mathrm{~W} ; 3-4.5 \mathrm{~W}) . \mathrm{V}=0.5 \mathrm{~mm} / \mathrm{s}$, $\lambda=0.98 \mu \mathrm{m}$.

The third FDF pattern is explained the formation of a through hole in the tissue. In this case, there is no more tissue pressure on the fiber tip, and the registered force is conditioned by the friction force at the fiber's lateral surface.

We have studied FDF with various laser radiation power and various speed of fiber movement into the depth of the tissue. Each piercing of the tissue was characterized by the maximum force registered by MSS. Fig. 3 shows the variation of the maximum FDF with respect to laser radiation power with perforation speed of $0.5 \mathrm{~mm} / \mathrm{s}$ for three wavelengths: $0.98 \mu \mathrm{m}, 1.56 \mu \mathrm{m}$ and $1.94 \mu \mathrm{m}$. Before each new perforation the fiber tip was split off (perforation with a "clean" fiber tip), and output radiation power was measured.

Fig. 3 shows that with $0.98 \mu \mathrm{m}$ wavelength there is a power range of $0-2.5 \mathrm{~W}$, where FDF almost does not change and coincides with the drag force during fiber perforation of the biological tissue in the absence of radiation $(\mathrm{P}=0 \mathrm{~W})$. FDF rapidly decreases in radiation 
power range of 2.5-3.5 W. With a wavelength of 1.94 $\mu \mathrm{m}$ there is no range where FDF does not change. Herewith, when the power is $2 \mathrm{~W}$, FDF is approximately ten times lower than in the absence of radiation. With higher radiation power (over $2.5 \mathrm{~W}$ for $\lambda=1.94 \mu \mathrm{m}$ and over $6 \mathrm{~W}$ for $\lambda=0.98 \mu \mathrm{m})$, FDF decreases below the limit of detection $(0.002 \mathrm{~N})$ of the mechanic sensor system.

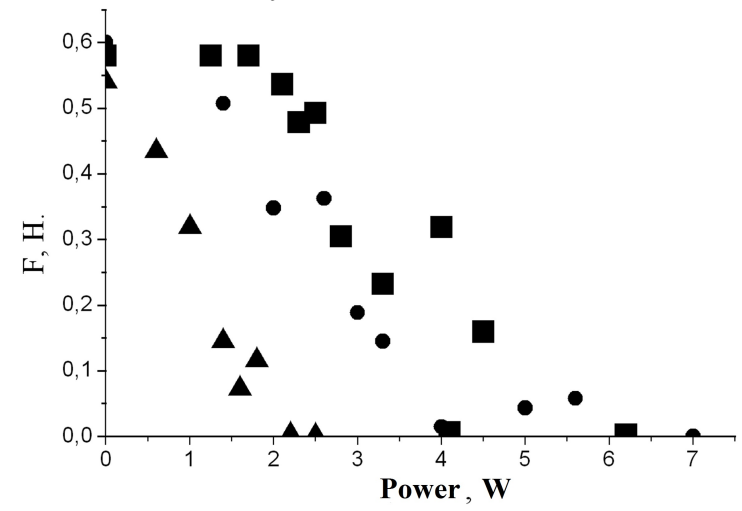

Fig. 3 Dependence of FDF on the power of laser radiation at different wavelengths $(\square-0.98 \mu \mathrm{m}$; - $-1.56 \mu \mathrm{m} ; \boldsymbol{\Delta}-1.94 \mu \mathrm{m}) . \mathrm{V}=0.5 \mathrm{~mm} / \mathrm{s}$.

This FDF behavior depending on the power of the laser radiation is conditioned by the forming of various thermal physical processes near the fiber tip. In the absence of radiation, the channel is formed due to mechanical tear of the tissue. If the power is increased, additional microexplosions may form near the fiber tip as bubbles appear, when water contained in the tissue begins to boil. As a result, less force is required to tear the tissue during fiber movement. If radiation power is further increased, the processes of intensive evaporation and tissue burning come into effect. In this mode, a channel is formed near the fiber tip due to intensive evaporation and tissue destruction caused by radiation. In these conditions, FDF is almost zero because the fiber tip has no contact with dense tissue. The drag force conditioned by friction of channel lateral walls may also significantly decrease in this mode, as the channel widens when tissue destruction products are discharged. As the tissue absorption coefficient is more than 100 times higher for a wavelength of $1.94 \mu \mathrm{m}$ than for a wavelength of $0.98 \mu \mathrm{m}$ [6], the thresholds for formation of micro tears and intensive evaporation are significantly lower for a wavelength of $1.94 \mu \mathrm{m}$.

FDF has such a broad range of fluctuations for two reasons. First, muscle tissue is not homogenous. Inter alia, the muscle tissue samples used may have blood vessels, fascia, fat tissue inclusions. The strength characteristics of these tissue components differ significantly: muscle tissue $-0.1-0.3 \mathrm{~N} / \mathrm{mm}^{2}$, blood vessels $-0.4-2 \mathrm{~N} / \mathrm{mm}^{2}$, skin $-2-36 \mathrm{~N} / \mathrm{mm}^{2}$, fascia $\left(12-14 \mathrm{~N} / \mathrm{mm}^{2}\right)$ [12-14]. Thus, when the fiber moves into the depth of the tissue, the FDF signal may fluctuate significantly, depending on which part of the perforated tissue it passes through. The second reason for the wide range of FDF figures is the non-steady nature of the perforation process, caused by non-steady heating, evaporation and the ejection of vapor and gas from the channel.

In the absence of radiation, the perforation process directly depends on the strength characteristics of the muscle tissue. In this case, FDF is $0.55 \pm 0.05 \mathrm{~N}$. With fiber diameter $600 \mu \mathrm{m}$ it corresponds to the pressure of $1.9 \pm 0.2 \mathrm{~N} / \mathrm{mm}^{2}$. This value is higher than the muscle tissue strength limit by an order of magnitude and approximately corresponds by the order of magnitude to the strength limit of vessel and skin tissue. We believe that the significant difference between FDF signal and muscle strength limit is explained by the fact that FDF is a pressure force, while the data related to strength limits of tissue components were determined by the force directed at tissue tear. When fiber exerts pressure on the tissue, there is a local redistribution of forces within the tissue. Force components directed at tissue tear also appear in this case, but they are naturally lower than the direct fiber pressure force.

Fig. 4 shows how FDF depends on fiber movement speed during perforation of the sample with radiation of $4 \mathrm{~W}$ and wavelength of $1.56 \mu \mathrm{m}$. This dependence also confirms conclusions regarding the different impact modes during perforation by laser fiber. When the fiber moves at low speeds, the tissue is considerably overheated, reaching high temperatures. This causes a vapor and gas channel to form near the fiber tip, and tissue destruction products are ejected along the lateral walls. In this case, the fiber almost does not touch the tissue, resulting in a quite low FDF. If the fiber movement speed increases, the tissue does not have the time to heat up to high temperatures, therefore no vapor and gas channel is formed and, as a result, the fiber mechanically touches the tissue, and FDF increases.

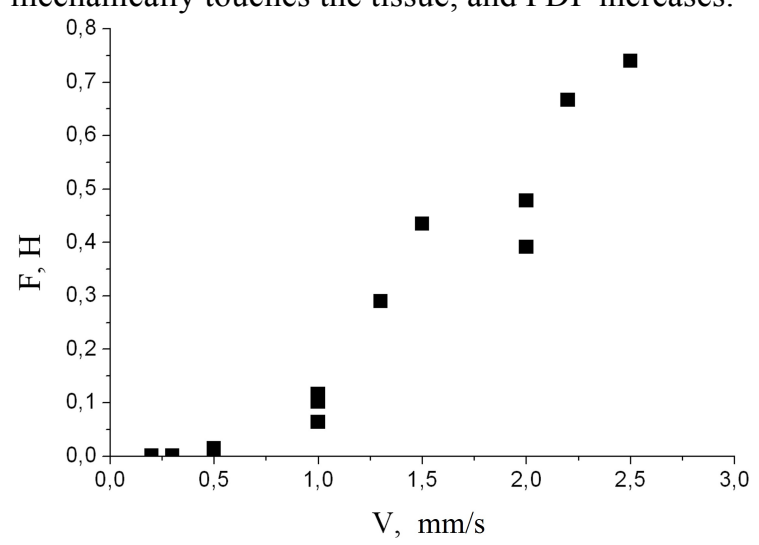

Fig. 4 Dependence of FDF on the speed of perforation of muscle tissue by laser fiber. $\mathrm{P}=4 \mathrm{~W}, \lambda=1.56 \mu \mathrm{m}$.

It is known that during laser perforation of the biological tissue with optic fiber, burnt tissue is deposited on the fiber tip as a result of tissue carbonization. This may lead both to decrease of radiation output from the fiber and to the fiber tip reaching high temperatures $[8,9]$. We have measured radiation power output, fiber tip heating temperature and FDF during 5 and more consecutive piercings of 
$1.5 \mathrm{~cm}$-thick biological tissue. In these experiments, the fiber tip was split off before the first perforation, and all the following perforations were done with non-split fiber. Power output and fiber tip temperature in the air (before touching the biological tissue) were measured before each consecutive perforation. It was discovered that in the process of perforation, the carbonized burnt tissue deposit at the fiber tip insignificantly decreases output radiation power (by 5-20\%), while fiber tip temperature may vary significantly within the range from $25-30{ }^{\circ} \mathrm{C}$ (in the absence of burnt tissue deposit at the fiber tip) to hundreds and even a thousand degrees Celsius. It was established that on average the significant burnt tissue deposit, manifesting itself in the high temperature of the fiber tip (over $100^{\circ} \mathrm{C}$ ), occurs after the third or fourth piercing of the $1.5 \mathrm{~cm}$-thick biological tissue. With such burn tissue deposit, FDF significantly decreases, in particular below the sensitivity limit of MSS sensor. Fig. 5 shows the variation of FDF with respect to time for the $2^{\text {nd }}, 3^{\text {rd }}$ and $4^{\text {th }}$ perforation and the corresponding fiber tip temperature.

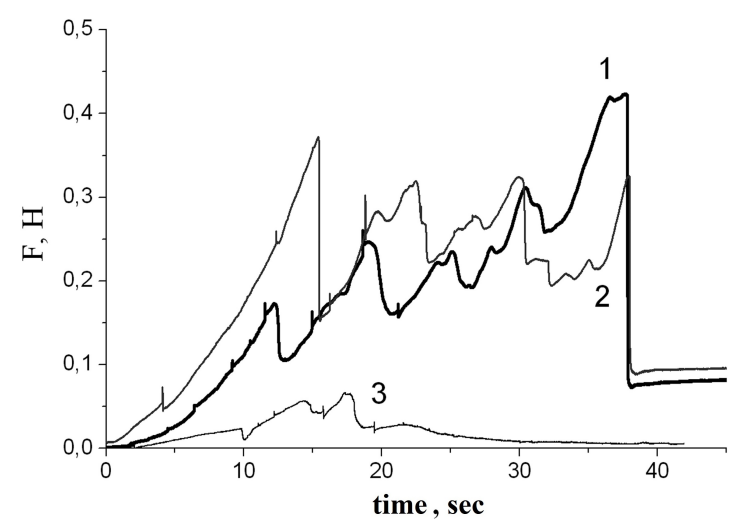

Fig. $5 \mathrm{FDF}$ as a function of time in the perforation of muscle tissue by laser fiber. 1 - perforation №2, $\mathrm{P}=2.6 \mathrm{~W}, \mathrm{~T}=85{ }^{\circ} \mathrm{C} ; 2-$ perforation №3, $\mathrm{P}=2.9 \mathrm{~W}$, $\mathrm{T}=85{ }^{\circ} \mathrm{C} ; 3$ - perforation №4, $\mathrm{P}=3.0 \mathrm{~W}, \mathrm{~T}=350{ }^{\circ} \mathrm{C}$. $\mathrm{V}=0.5 \mathrm{~mm} / \mathrm{s}, \lambda=1.56 \mu \mathrm{m}$.

When biological tissue is perforated, concentric layers of thermally damaged tissue are formed around the laser channel, where carbonization and coagulation zones may be singled out (Fig. 6b). The boundary of the coagulation zone corresponds to the visible borders of the tissue of whitish color [10]. The tissue changes its color due to protein denaturation, occurring at temperatures above $60{ }^{\circ} \mathrm{C}\left(60-70{ }^{\circ} \mathrm{C}\right.$ with heating time of $1-1000 \mathrm{~ms}$ ). More significant heating of the tissue up to the temperature of $300-400^{\circ} \mathrm{C}$ leads to its carbonization. The size of the carbonization area may also be determined visually (using a regular microscope), as a dark brown tissue layer which borders with the ablative zone (Fig. 6). The borders of coagulation zone determine the size of the thermally damaged area of the tissue.

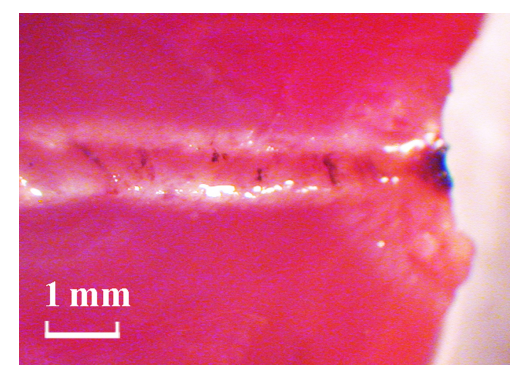

(a)

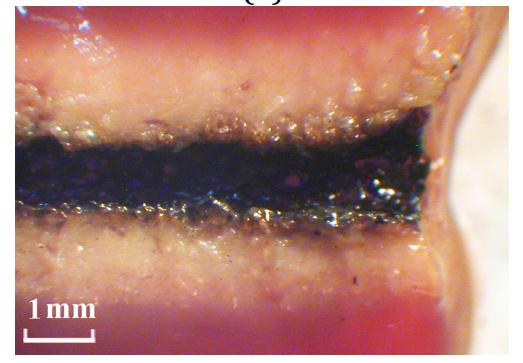

(b)

Fig. 6 Images of channels in biological tissues formed by a laser fiber. $\mathrm{V}=0.5 \mathrm{~mm} / \mathrm{s}, \lambda=0.98 \mu \mathrm{m}$. (a) $\mathrm{P}=3 \mathrm{~W}$; (b) $\mathrm{P}=8 \mathrm{~W}$.

Histograms on Figs. 7 and 8 show the variation of TDA width and laser channel (LC) diameter with respect to wavelength and laser radiation power. Sample perforation speed was maintained at a constant rate of $0.5 \mathrm{~mm} / \mathrm{s}$. The laser channel diameter, seen through the microscope (Fig. 7) is in some cases (with low laser radiation power and wavelengthof $0.98 \mu \mathrm{m}$ and $1.56 \mu \mathrm{m})$ smaller than the diameter of the laser fiber core, which is $600 \mu \mathrm{m}$. This is explained by the elasticity of the channel walls which sustained no significant thermal damage. In this case, the channel is formed due to tissue tear; later, the channel contracts naturally. Larger FDF corresponds to this power range (see Fig. 3). Increased radiation power leads to enlargement of the channel due to destruction and evaporation of the biological tissue along the fiber movement route (Fig. 7); simultaneously, drag force decreases (Fig. 3). The fiber moves freely in the tissue when the channel diameter increases to the size of the fiber core $(600 \mu \mathrm{m})$ and more, with laser radiation power of 5-6 W (Fig. 3).

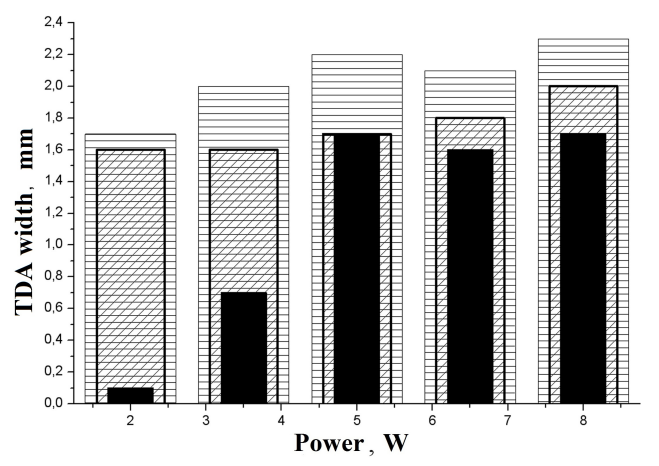

Fig. 7 Dependence of the TDA width on the wavelength and power of laser radiation. $(\mathbf{\square}-0.98 \mathrm{~m}$, $-1.56 \mathrm{~m}$, IIIII-1.94 m). 


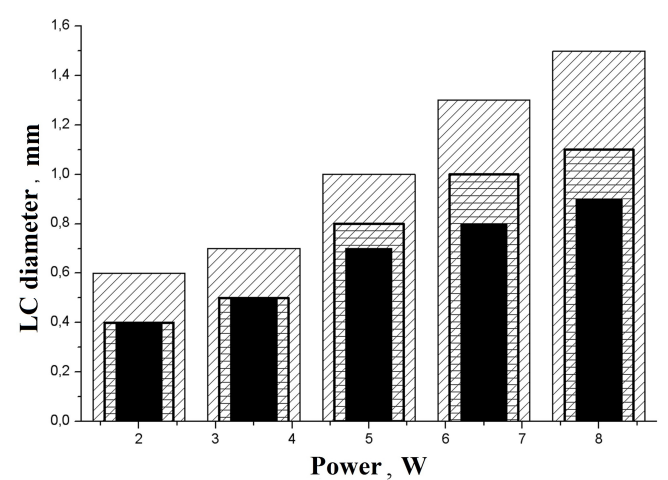

Fig. 8 Dependence of laser channel diameter on the wavelength and power of laser radiation. $(\mathbf{a}-0.98 \mathrm{~m}$, 器 $-1.56 \mathrm{~m}, \mathrm{IIIII}-1.94 \mathrm{~m})$.

\section{Conclusions}

The process of perforation of muscle tissue in vitro using near infrared laser radiation with optic fiber delivery was studied. The study of the drag force during movement of the fiber into the depth of the tissue makes it possible to distinguish three modes of tissue perforation:

1. Mechanical perforation mode: FDF almost does not depend on the laser radiation power and coincides with the drag force during piercing of the biological tissue with the fiber in the absence of radiation $(\mathrm{P}=0 \mathrm{~W})$. This mode was observed for $0.98 \mu \mathrm{m}$ wavelength in the power range of $0-2.5 \mathrm{~W}$ with constant perforation speed of $0.5 \mathrm{~mm} / \mathrm{s}$.

2. Intense evaporation and tissue destruction mode: FDF value drops as laser radiation power increases. This mode is applicable for all used laser sources. Its limits are primarily determined by laser radiation absorption efficiency of the biological tissue and fiber movement speed.

3. "Free" perforation mode: FDF is almost zero, as the fiber tip has no contact with dense tissue due to burning and evaporation of the biological tissue at the fiber tip and the increased diameter of the laser channel. "Free" perforation mode is applicable for 1.94 $\mu \mathrm{m}$ wavelength with power above $2 \mathrm{~W}$ and for wavelengths of 1.56 and $0.98 \mu \mathrm{m}$ with power above $4 \mathrm{~W}$.

It has been demonstrated that the drag force during muscle tissue perforation increases, if the speed of fiber movement into the depth of the tissue increases. When the fiber movement speed is low, the tissue becomes significantly overheated, and the third perforation mode is realized with FDF almost at zero value. If the speed of fiber movement into the depth of the tissue increases, the second mode gradually comes into effect with a gradual FDF increase.

Drag force measurement allows to evaluate the impact of carbonized burnt tissue deposit at the fiber tip on the perforation process. It has been established that on average burnt tissue deposit causing the fiber tip to heat up above $100{ }^{\circ} \mathrm{C}$ occurs after the third or fourth piercing of the biological tissue. With such burnt tissue deposit, FDF value drops to the sensitivity limit of the MSS sensor.

Channels formed during laser perforation of pig muscle tissue were examined with microscopes. Dependence of the thermal damage area and channel diameter on laser radiation power with perforation speed of $0.5 \mathrm{~mm} / \mathrm{s}$ was studied. Microscopic research of the biological tissue in the area of formed laser channels confirms the conclusion that there exist 3 various impact modes.

\section{Disclosures}

All authors declare that there is no conflict of interests in this paper.

\section{Acknowledgment}

This research was supported by grant No. 15-29-04816 of the Russian Foundation for Basic Research and by the Ministry of Science and Higher Education within the State assignment FSRC «Crystallography and Photonics» RAS (agreement No. 007-ГЗ/Ч3363/26) with regard to the determination method of tissue thermal damage area. 